\title{
Espiritualidade nexo qualidade de vida no trabalho: Um estudo subjetivo utilizando
}

\section{a metodologia Q}

\author{
Spirituality nexus quality of life at work: A subjective study using the Q methodology \\ Espiritualidad nexo de la calidad de vida en el trabajo: Un estudio subjetivo utilizando la \\ metodología Q
}

Recebido: 12/01/2022 | Revisado: 19/01/2022 | Aceito: 23/01/2022 | Publicado: 24/01/2022

\author{
Danúbia Leite Ferreira \\ ORCID: https://orcid.org/0000-0002-8808-6456 \\ Faculdade Internacional da Paraíba, Brasil \\ E-mail: danubialeite86@hotmail.com \\ Andreia Cavalcanti de Oliveira \\ ORCID: https://orcid.org/0000-0001-8610-8941 \\ Instituto Federal da Paraíba, Brasil \\ E-mail: andreia.oliveira@ifpb.edu.br \\ Olivia Dayse Leite Ferreira \\ ORCID: https://orcid.org/0000-0001-5298-8805 \\ Centro Universitário Uniesp, Brasil \\ E-mail: oliviadayse@yahoo.com.br \\ Maria de Lourdes Barreto Gomes \\ ORCID: https://orcid.org/0000-0003-0445-6710 \\ Universidade Federal da Paraíba, Brasil \\ E-mail: marilu@ct.ufpb.br
}

\begin{abstract}
Resumo
A espiritualidade nas organizações representa a realização de trabalho com significado, associada a ganho na qualidade de vida, entendida como subjetiva, centrada na experiência individual e com influência nas condições internas e externas ao sujeito. Deste modo, este artigo teve como objetivo analisar a percepção da espiritualidade no contexto organizacional, compreendendo os efeitos desta na qualidade de vida no trabalho. A pesquisa caracteriza-se por ser quali-quantitativa utilizando-se da metodologia $\mathrm{Q}$, que permite a descoberta de uma variedade de discursos sobre como os indivíduos compreendem a espiritualidade e a qualidade de vida. As observações foram efetivadas com onze docentes atuantes em diversas áreas do instituto. Os resultados mostraram quatro pontos de vista no sentido da espiritualidade para a qualidade de vida no trabalho, (1) estabilidade financeira, (2) satisfação profissional, (3) autodeterminação e (4) sentir-se útil. A aplicação da metodologia Q na análise constatou que o método permite uma abordagem responsiva, mas estatisticamente rigorosa, às percepções subjetivas das relações homem-espiritualidadequalidade de vida no trabalho, e seus resultados podem ser extremamente úteis para fomentar a formulação de políticas de gestão organizacional. Revelou ainda que a percepção dessa nova dimensão no ambiente de trabalho, contribui para subsidiar o entendimento da espiritualidade na construção e implementação de uma organização espiritualizada articulando com as necessidades práticas da gestão.
\end{abstract}

Palavras-chave: Espiritualidade; Qualidade de vida; Organizações.

\begin{abstract}
Spirituality in organizations represents meaningful work, associated with improved quality of life, understood as subjective, centered on individual experience and with influence on internal and external conditions to the subject. Thus, this article aimed to analyze the perception of spirituality in the organizational context, understanding the effects of this quality of life at work. The research is characterized by being qualitative-quantitative using the Q methodology, which allows the discovery of a variety of discourses on how to understand spirituality and quality of life. As presentations, they were made with eleven documents working in different areas of the institute. The results showed four points of view towards spirituality for quality of life at work, (1) financial stability, (2) job satisfaction, (3) self-determination and (4) feeling useful. The application of the Q methodology in the analysis of measures in the two studied constructs found that the method allows a responsive but statistically rigorous approach to the subjective perceptions of the man-spirituality-quality of life at work relationships, and its results can be used for promotion an organizational management policy. It also reveals that the perception of this new dimension in the work environment, contributes to the understanding of spirituality in the construction and implementation of a spiritualized organization, articulating with practical management practices.
\end{abstract}

Keywords: Spirituality; Quality of life at work; Organizations. 


\begin{abstract}
Resumen
La espiritualidad en las organizaciones representa un trabajo significativo, asociado con una mejor calidad de vida, entendido como subjetivo, centrada en la experiencia individual y con influencia en las condiciones internas y externas al sujeto. Así, este artículo tuvo como objetivo analizar la percepción de la espiritualidad en el contexto organizacional, comprendiendo sus efectos en la calidad de vida en el trabajo. La investigación se caracteriza por ser cualitativa y cuantitativa, utilizando la metodología $\mathrm{Q}$, que permite descubrir una variedad de discursos sobre cómo los individuos entienden la espiritualidad y la calidad de vida. Las observaciones se realizaron con once profesores que laboran en distintas áreas del instituto. Los resultados mostraron cuatro puntos de vista hacia la espiritualidad para la calidad de vida en el trabajo, (1) estabilidad financiera, (2) satisfacción laboral, (3) autodeterminación y (4) sentirse útil. La aplicación de la metodología Q en el análisis encontró que el método permite un abordaje sensible, pero estadísticamente riguroso, de las percepciones subjetivas de las relaciones hombre-espiritualidad-calidad de vida laboral, y sus resultados pueden ser de gran utilidad para fomentar la formulación de la gestión políticas organizacionales. También reveló que la percepción de esta nueva dimensión en el ambiente de trabajo contribuye a sustentar la comprensión de la espiritualidad en la construcción e implementación de una organización espiritualizada articulada con las necesidades prácticas de la gestión.
\end{abstract}

Palabras clave: Espiritualidad; Calidad de vida; Organizaciones.

\title{
1. Introdução
}

A palavra trabalho vem do latim, tripalium, que significa instrumento feito de três paus aguçados, algumas vezes munidos com ponta de ferro. A maioria dos dicionários registra o tripalium como um instrumento de tortura. (Albornoz, 2014)

Neste segmento o sentido originário da palavra trabalho está associado ao estado daquele que sofre, que é atormentado. Contudo, atualmente, o sentido certamente evoluiu, porém uma dimensão de limitação, pressão e constrangimento perdura através da noção de esforço: não existe trabalho sem que a atividade se apoie sobre uma mobilização de energia, uma tensão em direção a um objetivo. (Lhuilier, 2013)

$\mathrm{O}$ trabalho transforma o meio pelo qual se insere, promovendo aos indivíduos amparo e conforto além de produzir entre eles um significativo vínculo social para sua supervivência como trabalhado e indivíduo (Claudino et al., 2021). O homem busca um sentido ao trabalho, onde possa percebê-lo como uma ação individualizada, originada da sua experiência enquanto sujeito social e, ao mesmo tempo, uma percepção socialmente construída. Desta forma, ao realizar o trabalho, o homem transforma a natureza e é por ela transformado, seu produto o representa, a própria sociedade é criada e tem seus valores modelados pelas formas de produção. A partir desta visão do trabalho, observa-se que a satisfação advinda de sua realização se torna parte de uma construção multidimensional dentro do universo organizacional.

Segundo Claudino et al (2021), muitas vezes, o ambiente organizacional oportuniza experiências nem sempre prazerosas, ocasionando estresse que pode gerar em seus colaboradores doenças ocupacionais que não trazem apenas prejuízos profissionais e pessoais, mas também as organizações, que no invés de proporcionar incentivos, acabam perpassando por problemáticas, cotidianas, além do que se esperava. Assim, as organizações têm concentrado esforços para oferecer condições que favoreçam o desenvolvimento do ser humano no trabalho. No entanto, por se tratar de pessoas, conflitos, instabilidades de comportamento e motivações podem afetar diretamente os resultados do desempenho individual e coletivo. (Pinheiro et al, 2019). É neste contexto segundo a percepção de Ashmos e Duchon (2000) que o tema da espiritualidade é inserido no ambiente trabalho, a qual pode ser interpretada como o reconhecimento pela organização de que os empregados têm uma vida interior que alimenta, e é alimentada, pela realização do trabalho com significado num contexto de comunidade, que envolve ritos e símbolos.

Desta forma, a realização do trabalho busca contribuir para um propósito maior que os aspectos materiais, são pautados em valores éticos e centrados em princípios, formando uma visão compartilhada de contribuição à sua sociedade. (Tolfo et al., 2007). A literatura revela o crescente interesse e importância do estudo do tema da espiritualidade nas organizações como parte integrante da gestão por uma série de razões inerentes ao contexto do trabalho tais como: o 
comportamento ético, a satisfação no trabalho, a qualidade de vida, o comprometimento dos trabalhadores e a produtividade (Ashmos \& Duchon, 2000; Rego et al., 2007)

Assim, a pesquisa sobre a espiritualidade no local de trabalho busca contribuir na percepção dos fatores que na gestão organizacional possam aumentar a qualidade vida no trabalho refletindo diretamente no bem-estar dos indivíduos, da sociedade, das comunidades e da própria organização (Vasconcelos, 2008; Bezerra \& Oliveira, 2007). Portanto, Cunha, Rego e D’Oliveira (2006) reforçam que a espiritualidade no ambiente organizacional tem sido apontada como uma importante dimensão da qualidade de vida no trabalho influenciando de forma decisiva a experiência humana nas organizações.

Atualmente, as organizações começaram a perceber que o tema pode ser tratado como vantagem competitiva, compreendendo que as "respostas" procedidas de colaboradores "espiritualizados", auxiliam de maneira significativa no sucesso das organizações (Costa, 2014).

Neste sentido, o objetivo desse artigo é discutir o sentido da espiritualidade e da qualidade de vida no trabalho, buscando através de uma metodologia empírica respostas sobre a associação da espiritualidade e a qualidade de vida, onde provavelmente o equilíbrio espiritual poderá proporcionar um ambiente organizacional mais humano, refletindo em melhorias pessoais, como comprometimento, competência, produtividade e solidariedade, além de fortalecer a imagem e o status da instituição perante a sociedade.

\subsection{Espiritualidade no Ambiente Organizacional}

Na atualidade, os temas "Espiritualidade", "bem-estar físico, emocional, social e espiritual" e "qualidade de vida" são de grande interesse para a gestão organizacional, que tem como objetivo investigar em cada um deles o que há de psicológico, isto é, aquela faixa da realidade humana que não é puramente lógica nem biológica, mas exatamente psíquica (Rego, Souto, \& Cunha, 2007). Esses conceitos fazem parte da cultura contemporânea e, como tais, são entendidos por todos em seus sentidos gerais e frequentemente discutidos em suas acepções particulares.

Não há um consenso entre os pesquisadores sobre o que é espiritualidade. Portanto, os conceitos de espiritualidade e religiosidade ainda se confundem em muitos estudos (Breitbard, 2003; Rego et al., 2007; Vaillant, 2010). Embora alguns autores preferirem utilizá-los como sinônimos, outros, preferem fazer uma distinção bem clara entre ambos, porém, em todos os casos a espiritualidade acaba sendo um conceito mais amplo.

A utilização do termo espiritualidade separado de religião e religiosidade é bastante recente e teria ocorrido em torno das décadas 1960 e 1970, devido, entre outros fatores, à desilusão com as instituições religiosas. Geralmente, a religiosidade é considerada como incluindo crenças e práticas institucionalizadas, como por exemplo, frequência a cultos. Enquanto a espiritualidade estaria ligada à ênfase na experiência espiritual, na relação com a dimensão espiritual (Dalgalarrondo, 2008).

Segundo Koenig (2015), a espiritualidade é a "relação com o sagrado ou o transcendente (Deus, poder superior, realidade última)" (p.21). Para Dalgalarrondo (2008), a espiritualidade seria referente ao domínio do espírito, algo extra-físico, chamado na antiguidade de sobrenatural, uma relação pessoal com o transcendente. Sendo assim, a espiritualidade seria o termo mais geral e incluiria a religião, e seria um aspecto do núcleo da religião. Isso indicaria que existem indivíduos "espiritualizados", mas não religiosos ou ainda, que indivíduos extrinsecamente religiosos podem não ser especialmente espirituais.

Uma visão menos "religiosa" seria a de Lotufo Neto (1997) onde "espiritualidade trata da busca humana por uma vida satisfatória e com sentido, descobrindo a natureza essencial de si mesmo e seu relacionamento com o universo". Seria ainda o "Processo pelo qual os indivíduos reconhecem a importância de orientar suas vidas a algo não material que está além e é maior do que eles próprios, de modo a haver reconhecimento ou, pelo menos, alguma dependência a um poder superior, ou espírito". Envolveria um "processo pessoal dirigido a relacionar o si próprio com o poder superior essencial". 
Koenig (2015), define a espiritualidade como "a busca pessoal para respostas compreensíveis às perguntas finais sobre a vida, sobre seu significado, e sobre o relacionamento com o sagrado ou transcendental, e que pode (ou não pode) conduzir ou levar ao desenvolvimento de rituais religiosos e da formação de uma comunidade religiosa" (p. 32).

Porém, é Vaillant (2010), que traz à tona a relação da espiritualidade aos afetos positivos, caracterizando a espiritualidade como um amplo espectro de emoções positivas. Para ele espiritualidade seria então, "o amálgama de emoções positivas que nos une aos outros seres humanos e à nossa experiência com o divino, como quer que o concebamos" (p.5).

Partindo para o contexto organizacional, Rego et al. (2007) definem espiritualidade no local de trabalho, como as experiências espirituais que são vivenciadas pelos trabalhadores no local de trabalho resultantes da existência de um sentido de pertença a uma comunidade em que há a noção de préstimo para essa comunidade através do trabalho realizado num contexto de alinhamento de valores (individuais e organizacionais), alimentadas através das práticas espirituais (definidas no âmbito deste trabalho) implementadas na organização promovendo oportunidades de desenvolvimento, crescimento da espiritualidade de cada um.

Os autores sugerem que a espiritualidade no ambiente de trabalho pode incrementar o potencial intuitivo e criativo dos colaboradores, fomentar a honestidade e a confiança entre os membros organizacionais e entre eles e seus clientes, incrementar o sentimento de realização pessoal dos indivíduos, revigorar o empenho dos colaboradores na organização e promover o desempenho organizacional (Rego et al., 2007).

Waddock (1999) afirma que a "junção da mente, do coração, da alma e do corpo, individual e coletivamente (...) pode ajudar as empresas, públicas ou privadas, a reconhecer a importância da comunidade como base sobre a qual o sucesso, até mesmo a sobrevivência, pode ser construído" (p. 336).

Para Rueda et al. (2013), as organizações modernas têm assumido diversos papéis que buscam oferecer respostas em diferentes aspectos que vão além do material, como fornecer uma identidade, suprir necessidades afetivas, dar sociabilidade, desenvolver uma cultura organizacional que forneça um conjunto de valores que constituam um código, tentando despertar o amor e a devoção da sociedade. Todos estes itens influem diretamente na produção de um sistema simbólico que dá uma representação do ser humano, do que é valor da vida. As organizações bem-sucedidas compreendem o quanto que o ambiente de trabalho influencia os seus colaboradores e as consequências deste relacionamento são refletidas, e percebidas, por todos os seus trabalhadores, bem como pela própria organização (Oliveira et al., 2020).

Neste contexto, ao identificar as percepções de espiritualidade no ambiente de trabalho, as organizações podem resolver alguns dos seus problemas de insatisfação com o trabalho, absenteísmo, produtividade, comprometimento e qualidade de vida dos seus colaboradores. Desta forma, de acordo com Rego et al. (2007), torna-se responsabilidade dos gestores organizacionais darem conta do papel que as organizações têm na determinação do bem-estar das sociedades e dos indivíduos que a compõem. Ao avançar na investigação sobre a espiritualidade no local de trabalho e relacioná-la com a qualidade de vida no ambiente de trabalho, é possível contribuir para a construção de métodos e medidas que conduzam a um modelo de investigação que informe sobre a prática da mesma para a realização pessoal, melhoria da performance individual e, por conseguinte organizacional.

\subsection{Qualidade de Vida no Trabalho e Espiritualidade}

A origem dos estudos sobre Qualidade de Vida no Trabalho (QVT) é atribuída a Eric Trist e seus colaboradores que, em 1950, desenvolveram várias pesquisas no Tavistock Institute de Londres, com base na análise e reestruturação das tarefas, com o objetivo de tornar a vida dos trabalhadores menos penosa. Na década de 1950 e no decorrer da década de 1960 destacam-se os estudos de Abraham Maslow e Frederick Herzberg relacionados ao trabalho humano (Rodrigues, 2016).

De acordo com Lacaz (2014), na década de 1980, consolida-se uma tendência que baseia a QVT na maior 
participação do trabalhador na empresa, na perspectiva de tornar o trabalho mais humanizado. Os trabalhadores são vistos como sujeitos, estando sua realização calcada no desenvolvimento e aprofundamento de suas potencialidades. A QVT tem sido definida de diferentes formas por diversos estudiosos, no entanto, praticamente todas as definições têm em comum o entendimento de que a mesma objetiva propiciar uma maior humanização do trabalho, o aumento do bem-estar dos trabalhadores e uma maior participação dos mesmos nas decisões e problemas do trabalho (Rueda et al, 2013; Rodrigues, 2016).

Segundo Bom Sucesso (1998), a QVT refere-se à satisfação das necessidades do trabalhador afetando suas atitudes pessoais, sua capacidade de inovar ou aceitar mudanças no ambiente de trabalho e seu grau de motivação interna para o trabalho. Para o autor, o conceito de Qualidade de Vida no Trabalho é um conjunto de ações de uma organização que envolve diagnósticos e implantação de melhorias e inovações gerenciais, tecnológicas e estruturais, dentro e fora do ambiente de trabalho, visando propiciar condições plenas de desenvolvimento humano para e durante a realização do trabalho.

De acordo com Lacaz (2014), a saúde do trabalhador é essencial para o desenvolvimento de qualquer instituição, seja qual for o setor, portanto dentro do contexto do trabalho nos serviços públicos, garantir a qualidade de vida dos trabalhadores implica diretamente a satisfação e motivação para o trabalho, melhorando consequentemente a qualidade das atividades, da produtividade e dos serviços prestados à comunidade.

Formiga et al. (2019) aponta que a descoberta do fenômeno da espiritualidade pelas organizações e seus gestores e a valorização desta variável quanto construto psicológico ocorreu devido a importância que ela tem como mais um papel de destaque no desenvolvimento e manutenção de um ambiente destinado a um impacto positivo nas equipes.

As organizações que buscam a espiritualidade acreditam que os trabalhadores têm a sensação de poder, sentido, conexão e flexibilidade aumentada. Além disso, a espiritualidade no local de trabalho incorpora a noção de que as pessoas buscam significado no trabalho. (Ashomos \& Duchon, 2000).

Como afirma Branday, (2011) numa organização, enquanto a motivação incentiva à competição, a espiritualidade incentiva ao compartilhamento. Em uma organização voltada à motivação somente um profissional vence, enquanto numa que está voltada à espiritualidade todos os profissionais sobem ao pódio e, melhor ainda, todos cabem nele em primeiro lugar.

Como pôde ser visto, a qualidade de vida no Trabalho está associada à satisfação das necessidades do trabalhador, bem como a criatividade, flexibilidade e motivação do indivíduo no ambiente de trabalho. Observa-se também que o elemento da espiritualidade nas organizações, torna o ambiente mais saudável, incentiva os indivíduos a compartilharem e diminuir a competição e torna os indivíduos mais propensos para mudanças. Dessa forma, a espiritualidade nas organizações pode ser um indicativo para a qualidade de vida no trabalho.

\subsection{Metodologia Q}

A pesquisa que deu origem a este artigo empregou a metodologia $Q$, criada pelo físico e psicólogo inglês William Stephenson na década de 1930. Trata-se de uma metodologia apropriada à tradução empírica da heterogeneidade de ideias, perspectivas, crenças e conceitos subjetivos, caracterizando o estudo dos estados mentais e das manifestações comportamentais e opiniões dos sujeitos humanos. (Couto et al., 2011).

A metodologia Q tenta elucidar os diversos relatos ou discursos sobre ou em torno de um tema, assunto ou tópico específico do discurso (Barry \& Proops, 1999). Os autores afirmam que é apropriado para estudos de fenômenos sociais em torno dos quais há muito debate, conflito e contestação, pois tem como propósito gerar uma série de vozes, relatos e entendimentos, de modo, o diferencial da metodologia Q é a correlação entre as respostas individuais, extraindo formas de discurso "idealizadas" concentradas nos dados fornecidos pelos indivíduos compreendidos na pesquisa (Barry \& Proops, 1999)

Os dados fornecidos pelos indivíduos envolvidos na pesquisa são disponibilizados para ser utilizados estatisticamente 
(Mckeown et al., 1999; p. 12). Neste segmento, Pereira (2016) transcorre uma ressalva de Addams (2000) que "a metodologia Q combina a abertura dos métodos qualitativos com o rigor estatístico da análise quantitativa da pesquisa”, de tal modo, obtém a distinção entre pontos de vista característicos dos sujeitos e os que são compartilhados.

A metodologia $\mathrm{Q}$ é questionada quanto ao tamanho da amostra, o investigador tem de selecionar a amostra de forma suficientemente alargada, de modo a que esta seja representativa (Couto et al., 2011). Além disso, o autor mostra que o fato da metodologia usar pequenas amostras, esta sofreu algumas críticas, porém o autor explica que as análises não são baseadas no quantitativo de pessoas, mas sim no número de afirmações. Segundo o mesmo autor, o número de itens da amostra é variável, no entanto o mais frequente é esse item ser constituído por 40 a 50 afirmações. De acordo com Couto et al. (2011) a metodologia $\mathrm{Q}$ tem cinco procedimentos que estão citados na Figura 1.

Figura 1: Procedimentos da Metodologia Q.

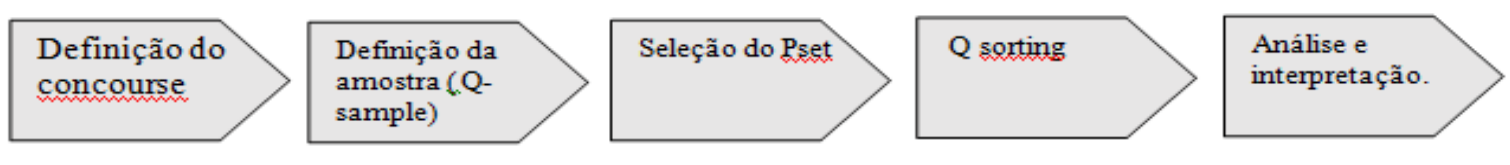

Fonte: Autores (2019).

A Definição do concourse trata-se da recolha de todas as afirmações que os participantes podem fazer sobre o tema em questão. A amostra Q sample é um conjunto inicial de afirmações construída na etapa Concourse que é apresentado aos participantes, além disso, o Q set (ou Q sample sob a forma de um conjunto de cartões numerados aleatoriamente, contendo cada um uma afirmação. A seleção de Pessoas (P set) que vão ordenar as afirmações. O Q sorting, refere-se a um o conjunto de participantes cujos Q-sort foram semelhantes, ou seja, que classificou as afirmações numa ordem semelhante de preferência, representando cada fator um tipo diferente de opinião. A análise e a interpretação dos dados serão feitas de acordo com a etapa de figura 1. Para mais detalhe ver a pesquisa (Couto et al, 2011).

Os dados fornecidos pelos indivíduos envolvidos na pesquisa são disponibilizados para serem utilizados estatisticamente (Mckeown et al., 1999; p. 12). Neste segmento, Pereira (2016) transcorre uma ressalva de Addams (2000) que "a metodologia Q combina a abertura dos métodos qualitativos com o rigor estatístico da análise quantitativa da pesquisa”, de tal modo, obtém a distinção entre pontos de vista característicos dos sujeitos e os que são compartilhados.

Assim, o presente estudo tem como objetivo de executar a metodologia Q para entender as opiniões subjetivas dos docentes de Instituição de Ensino, abordando a espiritualidade e como ela contribui para a qualidade de vida no trabalho.

\section{Metodologia}

O presente estudo trata-se de uma pesquisa descritiva, pois tal pesquisa observa, registra, analisa e ordena dados, sem manipulá-los, isto é, sem interferência do pesquisador. Procura descobrir a frequência com que um fato ocorre, sua natureza, suas características, causas, relações com outros fatos (Prodanov, 2013).

O campo da pesquisa escolhido trata-se de docentes do Instituto Federal localizado no Estado da Paraíba. O universo da pesquisa refere-se a 38 docentes. Sendo que 11 participaram da pesquisa.

\subsection{Etapas do uso da metodologia $Q$}

Segundo Barry e Proops (1999) a metodologia Q é comumente utilizada em seis etapas, conforme a Figura 2, abaixo: 
Figura 2. Etapas da Metodologia Q.

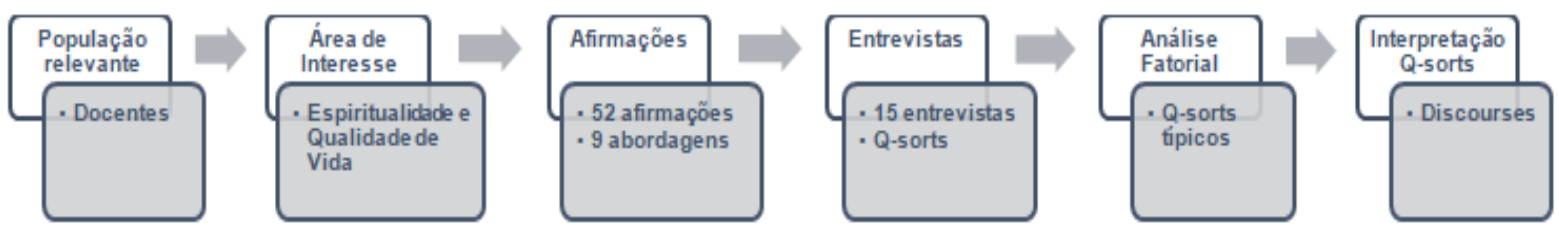

Fonte: Autores (2019).

Inicia-se identificando as áreas do estudo que vão ser exploradas e os participantes teoricamente relevantes. O objeto de estudo escolhido nesta pesquisa, foram a espiritualidade e a qualidade de vida no trabalho nas organizações, e a população alvo constituiu-se de docentes que advêm de uma variedade de cursos das exatas e das humanas.

No segundo momento, é obtidas afirmações a partir da revisão da literatura ou de entrevistas estruturadas com uma amostra da população. Discorre de um levantamento de todas as afirmações que os participantes podem fazer sobre o discurso em questão (Couto et al., 2011). Trata-se de afirmações que são a base para a futura análise realizada para entender as construções subjetivas da espiritualidade para a qualidade de vida. No caso da presente pesquisa, para cumprir essa etapa, foi utilizado o conteúdo da revisão de literatura.

$\mathrm{Na}$ terceira etapa são selecionadas as afirmações para uso nos Q-sort (matriz), assim, surgi uma análise mais aprofundada das declarações recolhidas (Couto et al., 2011) que são a posteriori apresentadas aos entrevistados. As afirmações selecionadas são compostas por duas escalas construídas e validadas, a da espiritualidade nas organizações por Rego, Souto e Cunha (2007) e a escala de avaliação da qualidade de vida no trabalho por Rueda et al. (2013). Foram selecionados 52 itens (afirmações) para a amostra, conforme a Figura 3, dividida em nove abordagens: 1) sentido de comunidade; 2) valores da organização; 3) sentido de comunidade; 4) alegria no trabalho; 5) vida interior; 6) integração, respeito e autonomia; 7) compreensão justa e adequada; 8) lazer e convívio social e 9) incentivo e suporte. Não existe um número ideal e classificação perfeita das afirmações nos tópicos, uma vez que os resultados não vão reproduzir esses tópicos, pois cada participante usará as afirmações independentemente para indicar a importância /relevância segundo o seu próprio ponto de vista.

A quarta etapa, seleciona-se os sujeitos da pesquisa, tal amostra composta por 11 servidores públicos que atuam na docência no Instituto Federal de Educação Tecnológica da Paraíba, no universo de 38 docentes da área de exatas e de humanas. Os participantes da pesquisa precisavam ter no mínimo seis meses de atuação em docência, por se entender ser esse um período mínimo necessário para permitir descrições confiáveis do clima organizacional percebido pelos indivíduos. A amostragem utilizada neste estudo foi caracterizada como não probabilística por conveniência, pois a seleção dos indivíduos foi de acordo com a disponibilidade, e inicialmente o pesquisador desejava alcançar o maior número de entrevistados possível. Vale ressaltar que o tamanho da amostra foi definido de acordo com a metodologia $\mathrm{Q}$, a qual utiliza uma amostra pequena, pois a partir de um determinado número de afirmações as perspectivas se repetem não introduzindo novas ideias. Além disso, na metodologia Q, os inquéritos na população geral, a validade estatística não é a maior preocupação, uma vez que os resultados de um estudo Q são as diferentes opiniões (subjetivas) sobre o tema que está a ser operacionalizado, e não a percentagem da população que adere a cada uma dessas opiniões (Couto et al., 2011). Na realização do convite para os entrevistados, não foi mencionado que a pesquisa visa entender sobre espiritualidade e sim somente qualidade de vida no trabalho, pois foi entendido que a utilização da palavra espiritualidade poderia influenciar o resultado buscado na pesquisa, uma vez que o termo logo remete ao sentido de religiosidade.

Prosseguindo, as afirmações foram expostas aos respondentes em forma de cartões numerados para serem distribuídos em um tabuleiro (Figura 3), sendo instruídos para elencar as 52 afirmações conforme a intensidade com que concordam ou 
discordam, em uma escala de nove pontos. Para isso, devem posicionar as afirmações dentro de matriz apresentada na Figura 3.

Figura 3. Matriz.

\begin{tabular}{|c|c|c|c|c|c|c|c|c|}
\hline \multicolumn{4}{|c|}{ Mais Rejeita } & Nulo & \multicolumn{4}{|c|}{ Mais Concorda } \\
\hline-4 & -3 & -2 & -1 & 0 & 1 & 2 & 3 & 4 \\
\hline & & & & & & & & \\
\hline & & & & & & & & \\
\hline & & & & & & & & \\
\hline & & & & & & & & \\
\hline & & & & & & & & \\
\hline & & & & & & & & \\
\hline & & & & & & & & \\
\hline & & & & & & & & \\
\hline
\end{tabular}

Fonte: Autores (2019).

Conforme ilustração o tabuleiro tem nove colunas, correspondendo a 4 " concordar com mais força" e -4 "discordar com mais força". O número de declarações correspondentes a cada força foi limitado antecipadamente, compreendendo uma distribuição forçada. Conforme Lucinski (2016) a fixação das afirmações com poucas opções para concordar e discordar totalmente, seguindo a estrutura piramidal, encoraja os participantes a considerarem com atenção o ranking das afirmações, refletindo sobre o próprio ponto de vista referente ao tema. Assim, constitui-se a classificação das afirmações por indivíduo, a matriz Q-sort, complementada com uma descrição breve do respondente sobre o assunto, com intuito de facilitar a análise do pesquisador, e também servir como confirmação da precisão da análise feita.

E na quinta etapa, é a fase da análise fatorial dos Q-sorts dos entrevistados, revelando quais indivíduos fazem parte de cada ponto de vista, e a "força" dessa ligação, ou seja, extraem-se os Q-sorts típicos, um "tipo ideal" em torno do qual os tipos Q que mais se aproximam desse ideal são listados. Para essa etapa foi utilizado o software PQMethod 2.35, projetado especialmente para a Metodologia Q.

Operacionando o software é digitado cada uma das matrizes obtidas como entrada de dados. Assim, é calculada a correlação de cada Q sort com todos os outros Q sort, essa correlação é posta em uma análise fatorial pela centróide. A função "Varimax Rotation" disponível no software operaciona a análise fatorial obtida para uma estrutura simples, obtendo fatores que são expressivos conforme protocolo da metodologia Q. Por fim, esses fatores são reformulados como uma "melhor estimativa" do Q-sort que os representa, apontado como Q-sort típico. Observa-se que um determinado participante pode estar disposto por mais de um Q-sort típico, uma vez que os Q-sorts típicos são desenvolvidos com base nas matrizes dos entrevistados.

E na última etapa, a sexta, para conseguir explorar os fatores (o pesquisador faz uma interpretação qualitativa, entendendo o que subjaz às combinações de afirmações que diferenciam um fator dos outros, para isso utilizou-se das observações e descrições do participante sobre o discurso nas entrevistas. Essa discussão procura cooperar para a construção subjetiva do raciocínio de cada Q-sort "ideal”, denominado pela metodologia de Discourse (Lucinski, 2016). Dessa forma, para identificar os fatores dessa pesquisa, inicialmente, extraíram-se oito fatores do programa PQMethod 2.35, que não foram rotacionados, representando $95 \%$ da variância total.

Para determinar o número de fatores a serem rotacionados, foi utilizada uma combinação de práticas sugerida por Brown (1980) do critério do valor próprio (eigenvalue excedendo 1). A solução indicou quatro fatores, que foram definidos pelos pesquisadores como: Estabilidade Financeira (A), Satisfação Profissional (B), Autodeterminação (C) e Sentir-se Útil (D). Esses fatores para girar, com $74 \%$ da variância total, o primeiro refletindo a posição de 3 pessoas, com variância de $22 \%$, o 
segundo fator considerando o posicionamento de 2 indivíduos, representando $19 \%$ da variância, o terceiro refletindo a posição de 4 pessoas, com $20 \%$ da variância e o quarto a posição de 2 pessoas, representando $13 \%$ da variância.

A correlação foi significativa entre os fatores A e $C(r=0,42)$ e entre os fatores $C$ e $B(r=0,41)$, provavelmente um resultado da semelhança básica da situação de todos os docentes, entretanto, notam-se nítidas divergências de fácil percepção, conforme fatores apresentados a seguir. Os discursos em regra, não representam nenhum indivíduo em particular, e sim, uma versão "pura" ou "tipo ideal" de uma maneira de ver o mundo.

Nesse contexto, a utilização da metodologia Q proporciona a exposição de perfis semelhantes de indivíduos que compartilham ideias, independentemente das categorias tradicionais demográficas, como sexo e idade. Nesse estudo, a utilização da metodologia revela uma hierarquia da importância relativa dos vários aspectos da relação entre espiritualidade e qualidade de vida, identificando pontos de vista compartilhados dos docentes com relação ao tema.

\section{Resultados}

Nessa etapa são apresentados os Q-sorts típicos identificados e assim demonstram-se a interpretação, dos autores, dos fatores encontrados e sintetiza as principais divergências e semelhanças dos pontos de vista do discurso.

\subsection{Fator A: Estabilidade Financeira}

Para este ponto de vista as seguintes afirmações são particularmente importantes: concordância, 38, 51, 5 e 52; discordância, 6, 19, 20 e 40. O ponto característico nessa opinião está relacionado a questões financeiras, destacando a estabilidade financeira proporcionada pela instituição, pois proporciona satisfação e realização de suas vontades, destaque, principalmente, a possibilidade de lazer e convívio social. Entretanto, revela-se também essencial no ambiente de trabalho o espírito de equipe e o zelo mútuo entre os seus membros.

\subsection{Fator B: Satisfação Profissional}

As afirmações destacadas particularmente importantes: concordância, 32, 11 e 24; discordância, 4, 19, 38, 6 e 40, revelam que a satisfação profissional é essencial para se sentir bem, mesmo sem o retorno financeiro e incentivos da organização. $\mathrm{O}$ trabalho se configura como elemento satisfatório para a sua vida pessoal e profissional.

\subsection{Fator C: Autodeterminação}

Para este ponto de vista as seguintes afirmações são particularmente importantes: concordância, 2, 14 e 24; discordância, 6, 30, 19 e 18. O bem estar profissional, para o perfil C, está relacionado quando a organização proporciona respeito, autonomia, integração e oportunidades para a vida interior. Assim, quando as organizações criam ambientes que possibilitam aos seus colaboradores satisfazer suas necessidades espirituais, estes se sentem mais respeitados e autodeterminados.

\subsection{Fator D: Sentir-se útil}

As afirmações são particularmente importantes: concordância, 11, 14, 5 e 21; discordância, 30, 41, 32 e 18. A análise dessa visão demonstra essencial a compatibilidade dos valores da vida interior do indivíduo com os valores da organização, assim como o sentimento de utilidade para com a sociedade. Esses se sentem "interiormente" alinhados com a organização quando ela se mostra preocupada com um todo (sociedade). A Figura 4 ilustra com clareza essa análise. 
Figura 4. Resultados do Q-sorts típicos.

\begin{tabular}{|c|c|c|c|c|c|}
\hline & \multirow{2}{*}{ AFIRMACCÖES } & \multicolumn{4}{|c|}{ Q-SORTS TIPICOS } \\
\hline & & A & B & $\mathrm{c}$ & $\mathrm{D}$ \\
\hline 1 & Sinto-me bern corn as valores que predorninam na mintha organizaçäo. & +3 & -1 & +3 & 0 \\
\hline 2 & Tenho autonomia para reaizzar meu trabalho & +3 & +2 & +4 & +1 \\
\hline 3 & As pessoas do meu grupolequpe sentem-se parte de uma farnilia & +3 & 0 & $\cdot 3$ & -2 \\
\hline 4 & A crganizaçăo oferece reajustes salariais adequados & +3 & -4 & -1 & 3 \\
\hline 5 & Minha carga horária é adequada & +4 & +3 & +1 & +4 \\
\hline 6 & A organizaçâo oferece oportunidades de fazer horas extras & -4 & -4 & -4 & -1 \\
\hline 7 & O meu grupolequpe fomenta a criaçào de um espirto de comunidade & +1 & 0 & +3 & 0 \\
\hline 8 & A mirha organizaçăo ajuda-me a que eu viva em paz comigo mesmo & 0 & +1 & +1 & -2 \\
\hline 9 & As normas e regras săo claras e bem definidas & +1 & 0 & $\cdot 3$ & -1 \\
\hline 10 & Minha vida pessoal é respehada & +1 & +1 & $\cdot 4$ & 0 \\
\hline 11 & Com minha jomada de trabaiho tenho tempo para me dedicar a familia & +2 & +4 & 0 & +4 \\
\hline 12 & As atividades que devo executar sào planejadas com antecedéncia & +2 & +2 & +1 & +1 \\
\hline 13 & Acredto que as pessoas do meu grupolequipe se apoiam urnas as outras. & +3 & +1 & +2 & 0 \\
\hline 14 & Quando trabalho, sinto que sou úti a sociedade. & +2 & +2 & +4 & +4 \\
\hline 15 & Os funcionários são respeitados independente de serem homens au mulheres & -1 & +1 & +3 & +2 \\
\hline 16 & A liberdade de expressão è respeitada & 0 & -1 & $\cdot 1$ & +1 \\
\hline 17 & Meu trabalho permete ter momentos de lazer com a familia & +1 & +3 & 0 & +3 \\
\hline 18 & A organizaçào promove treinos penódicos & -3 & 0 & -4 & -4 \\
\hline 19 & A organizaçào oferece ginàstica laboral & -4 & -4 & -4 & 0 \\
\hline 20 & Acredto que os membros do meu grupolequipe se preocupan reaimente uns c & -4 & +1 & 0 & 0 \\
\hline 21 & O trabalho que eu realizo esta relacionado com aquilo que considero importante & -3 & +3 & +2 & +4 \\
\hline 22 & Os funcionarios se respetam independente do cargo que ocupam & -3 & +2 & -3 & -1 \\
\hline 23 & Os colegas de trabalho me ajudam quando preciso & 2 & +3 & 0 & +1 \\
\hline 24 & Sou respeitado(a) peios colegas de trabaho & 0 & +4 & +4 & +2 \\
\hline 25 & O saláno que recebo permite satisfazer as minhas vontades & -3 & -3 & -2 & +2 \\
\hline 28 & Após minha jomada de trabalho tenho disposicào para realizar outras atividades & -3 & +2 & -2 & -1 \\
\hline 27 & A organizaçä̀ oferece possibilidade de promoçōes para os funcionávios & -2 & -1 & +2 & +3 \\
\hline 28 & Sinto que as pessoas do meu grupolequpe estalo ligadas ertre si por um propo & -2 & -1 & 0 & -2 \\
\hline 29 & A minha organizaçáo respeita a minha "vida interior". & 0 & -1 & +2 & +1 \\
\hline 30 & Os meus valores espirtuais nāo sâo valorizados no meu local de trabaiho. & -2 & 0 & -4 & -4 \\
\hline 31 & Sou incentivado(a) a reaizar cursos de aperfeiçoamento. & -1 & 3 & +1 & -1 \\
\hline 32 & Sinto alegna no meu trabalho. & +2 & +4 & $\cdot 2$ & -4 \\
\hline 33 & No meu locai de trabalho, năo ha lugar para a minha espirtualidade. & $\rightarrow 1$ & -1 & -3 & 0 \\
\hline 34 & Meus diretos sbao respentados & 0 & +2 & +2 & -2 \\
\hline 35 & As responsabisidades que tenho sjo adequadas a minha funça & +2 & +3 & -1 & +2 \\
\hline 38 & Ideias sầ compartilhadas entre os colegas & +1 & -1 & -2 & -1 \\
\hline 37 & Meu salário ê justo para o esforço (fisico ou mental) que realizo & +3 & -3 & 0 & +3 \\
\hline 30 & Estou feliz com o salario que recebo & $\bullet 4$ & -4 & -1 & +2 \\
\hline 39 & Meu horario de trabalho permite programar atividades com antecedéncia & +1 & 0 & -2 & +1 \\
\hline 40 & As horas extras säo pagas. & -4 & -4 & -3 & 0 \\
\hline 41 & As pessoas sentem-se bem acerca do seu futuro na orgarizaçăo. & 0 & -2 & 0 & -4 \\
\hline 42 & Vejo que existe urria ligaçäo entre o meu trabaiho e 05 beneficios para a sociedi & +1 & 0 & +1 & +1 \\
\hline 43 & A organizaçẫo incentiva o respeito entre os funcionărios & 0 & 0 & +1 & -1 \\
\hline 44 & Tenho autonomia para tomar deciscoes & -1 & +1 & -1 & 3 \\
\hline 45 & Os lideres da minha organizaç ăo preocupam-se em ser ütess a sociedade. & -1 & -2 & -1 & .2 \\
\hline 46 & Na maior parte dos dias, e com prazer que venho para o trabalho. & -2 & +3 & -2 & -2 \\
\hline 47 & O horario de trabalho favorece o convivio social fora da organizaça & -2 & +1 & -1 & +3 \\
\hline 48 & A organizaçāo me incentiva a realizar atividades culturais" & -1 & -3 & -3 & 3 \\
\hline 49 & A religiảo dos funcionários è respertada & -1 & -2 & -1 & 3 \\
\hline 50 & Tenho clareza dos meus direitos e deveres na organizaçăo & 0 & -2 & D & +2 \\
\hline 51 & Meu salärio ê justo para a experiencia profissional que possuo & +4 & 2 & .2 & 3 \\
\hline 52 & Meu salario e adequado quando comparado ao de outras organizaçoes & +4 & -2 & -3 & +3 \\
\hline
\end{tabular}

Fonte: Autores.

\section{Discussão}

Percebe-se que para cada respondente o tema reflete controvérsias no ambiente organizacional, a inclusão da espiritualidade trouxe uma perspectiva de tema inédito na pesquisa acadêmica para alguns participantes, que entendem a espiritualidade apenas com sentido religioso. Portanto, Rego et al. (2007) afirmam que a espiritualidade e religião não são sinônimos. Pois ser alguém espiritual não significa exibir qualquer religião. E uma organização que nutre a espiritualidade não é a que induz as pessoas a adotarem determinadas crenças e práticas religiosas. Dessa forma, observa-se que o conceito espiritualidade, caso a organização tenha interesse, deve ser muito bem trabalhado e definido para os membros de uma organização.

No contexto dos fatores definidos, após a aclaração dos quatro pontos de vista, percebe-se que o fator "A" converge à gênese da palavra trabalho, "tripalium", demonstrando que o laboro é algo que não é realizado apenas pelo prazer, mas por uma questão de necessidade, reforçando assim o significado real da palavra. O fator "A" tem maior correlação com o fator 
"C", revelando uma percepção de pontos de vista semelhantes. Lembrando que o fator A é definido como a Estabilidade Financeira e o fator $\mathrm{C}$ a autodeterminação.

O fator "C" também demonstra relação com o fator "B", a satisfação profissional tem aspectos semelhantes com a visão de autonomia. Enquanto o fator "D" apresenta-se com maior divergência entre os demais pontos de vista, refletindo uma visão em que consideram o trabalho com significado e útil a sociedade, compreendendo que a organização lhes faculta oportunidades para a vida interior. Este resultado mostra o que (Ashmos \& Duchon, 2000) afirmam que a espiritualidade no local de trabalho incorpora a noção de que as pessoas buscam significado no trabalho.

Portanto, todos os Q-sorts típicos apresentam traços que relacionam a espiritualidade com a qualidade de vida no trabalho, porém, é notável o foco nas dimensões da QVT nas organizações, proporcionando diferenças claras, estatisticamente distintas, o que permitiu uma compreensão melhor das opiniões e crenças. A figura 4 demonstra os resultados do Q-sorts típicos.

\section{Conclusão}

A partir da aplicação da metodologia Q para analisar as dimensões de espiritualidade organizacional para a qualidade de vida no trabalho, observou-se que o método permite uma abordagem responsiva, mas estatisticamente rigorosa, às percepções subjetivas das relações homem-espiritualidade-QVT, e seus resultados podem ser extremamente úteis para fomentar a formulação de políticas de gestão organizacional.

A hierarquização forçada dos itens permitiu avaliar a importância individual e subjetiva de cada item em relação a todos os outros, admitindo comparação. As opiniões foram correlacionadas, mas distintas. O uso da metodologia Q também revelou as semelhanças de perfil das pessoas que compartilham ideias, independentemente das categorias tradicionais demográficas, como sexo e idade.

Os resultados na pesquisa revelaram quatro pontos de vista referentes à espiritualidade para a qualidade de vida no trabalho. O primeiro A, caracterizado por enfocar a estabilidade financeira, o B, a realização profissional, embora enfatize o não retorno financeiro, já o $\mathrm{C}$, faz alusão à autonomia e independência proporcionada pela organização, por fim, o D demonstra-se uma visão de comunidade, sentindo-se útil a sociedade.

A utilização do método de pesquisa originou algumas limitações ao estudo, devendo as entrevistas ter sido aplicada com maior número de pessoas para a obtenção de resultados estatísticos com maior significância, isso conforme Barry e Proops (1999) a partir de doze participantes as implicações são mais claras.

Nesse contexto, este estudo revela a percepção dessa nova dimensão no ambiente de trabalho, contribuindo assim para subsidiar o entendimento da espiritualidade na construção e implementação de uma organização espiritualizada articulando com as necessidades práticas da gestão. Assim, uma conduta espiritualizada no ambiente organizacional, onde converge o pertencimento e a empatia, pode direcionar a uma qualidade de vida no trabalho elevada, pois tais constructos contribuem no aumento da motivação influenciando assim na produtividade organizacional, pontos positivos da QVT. Vale ressaltar que em futuras pesquisas a escolha de outras técnicas de amostragem pode melhorar os resultados.

Destarte, por ser a temática de vasta amplitude, entende-se por oportuno dar continuidade a futuras pesquisas, a serem realizadas no âmbito organizacional, tanto no setor público como também privado, engajando-se profissionais de diferentes áreas de conhecimento para melhor entendimento da temática, tornando-se um trabalho interdisciplinar. Além disso, pode ser possível avaliar o tema espiritualidade e qualidade de vida no trabalho usando métodos quantitativos e amostragens probabilísticas, pois se observou que o tema pode ser explorado de várias formas. 


\section{Referências}

Albornoz, S. G. (2014). O que é trabalho? Ed. Brasiliense.

Ashmos, D. P., \& Duchon, D. (2000). Spirituality at Work: A Conceptualization and Measure. Journal of Management Inquiry, 9(2), 134-145. https://doi.org/10.1177/105649260092008

Barry, J. \& Proops, J. (1999) Seeking sustainability discourses with Q methodology. Ecological Economics, 28 (3), $337-345$.

Bezerra, M. F. N., \& Oliveira, L. M. B. (2007). Espiritualidade nas organizações e comprometimento organizacional: estudo de caso com um grupo de líderes de agências do banco do brasil na cidade de Recife. In: XXXI ENANPAD, Anais. Anpad,

Brown, S. R. (1980). Political Subjectivity: Applications of Q Methodology in Political Sci- ence. Yale University Press, New Haven.

Couto, M., Farate, C., Ramos, S., \& Fleming, M. (1969). A Metodologia Q nas Ciências Sociais e Humanas: O resgate da subjectividade na investigação empírica. PSICOLOGIA, 25(2), 7-21. https://doi.org/10.17575/rpsicol.v25i2.285

Costa, Q. (2014). Reflexões sobre a espiritualidade nas organizações. X Congresso Nacional de Excelência em Gestão.

Claudino, D. T. F., Souza, G. M. R. de, Silva, A. C., \& Silva, J. F. (2021). O impacto de Programas de Qualidade de Vida no Trabalho em tempos de crise. Research, Society and Development, 10(17), e232101724881. https://doi.org/10.33448/rsd-v10i17.24881

Cunha, M. P., Rego, A., \& D’Oliveira, T. (2006). Organizational spiritualities. An ideology-based typology.Business \& Society, $45(2), 211-234$.

Dalgalarrondo, P. (2008). Religião, Psicopatologia e Saúde Mental. Artmed.

Da Silva, P. L. A. \& Da Silva, B. F. G. (2015). Liderança na UNIMED Caruaru: Percepção dos líderes acerca do seu papel na organização. Interfaces de Saberes, $14(1)$.

Egan, T. M. (2005). Factors Influencing Individual Creativity in the Workplace: An Examination of Quantitative Empirical Research. Advances in Developing Human Resources, 7(2), 160-181. https://doi.org/10.1177/1523422305274527

Filho, A. G., \& Blikstein, I. (2013). Comunicação assertiva e o relacionamento nas empresas. GV-executivo, 12(2), 28. https://doi.org/10.12660/gvexec.v12n2.2013.20706

Formiga, N. S., Araújo, I. T., Oliveira, B. F., Pastana, S. T., Guedes, M. A. L., Azevedo, I. M., \& Mafra, A. L. (2019). Suporte organizacional, engajamento e espiritualidade no trabalho: verificação empírica de um modelo teórico concorrente em organizações brasileiras. Boletim - Academia Paulista de Psicologia, 39(97), 247-259. Disponível em: http://pepsic.bvsalud.org/scielo.php?script=sci_arttext\&pid=S1415-711X2019000200010\&lng=pt\&tlng=pt

Gelis Filho, A. \& Blikstein, I. (2013). Comunicação assertiva e o relacionamento nas empresas. GV Executivo, 2 (2), 28 -31.

Giacalone, R. A., \& Jurkiewicz, C. L. (2003).Handbook of Workplace Spirituality and Organizational Performance. New York: M.E. Sharpe.

Gil, A. C. (2008). Métodos e técnicas em pesquisa social. Atlas.

Hair, J. F., Black, W.C., Babin, B.J., Anderson, R. E., \& Tathan, R. L. (2009). Análise Multivariada de Dados (6a ed.). Bookman.

King, J. E., \& Crowther, M. R. (2004). The measurement of religiosity and spirituality: Examples and issues from psychology. Journal of Organizational Change Management, 17(1), 83-101. https://doi.org/10.1108/09534810410511314

Koenig, H. G. (2015). Medicina, Religião e Saúde: o encontro da ciência e da espiritualidade. (2a ed). L\&PM.

Lacaz, F. A. C. (2014). A Saúde/Adoecimento do Trabalhador em Saúde: aspectos teórico-conceituais. BIS - Boletim do Instituto de Saúde, 15, 27-33. Disponível em: https://www.saude.sp.gov.br/resources/instituto-de-saude/homepage/bis/pdfs/bisvol15-n2.pdf

Lhuilier, D. (2013). Trabalho. Psicologia \& Sociedade, 25(3), 483-492. https://doi.org/10.1590/S0102-71822013000300002

Lotufo Neto, F. (1997). A Prevalência de Transtornos Mentais entre Ministros Religiosos. Faculdade de Medicina da Universidade de São Paulo. Departamento de Psiquiatria.

Lucinski, M. D. A. P. (2016). Competências de gestores de projetos voltadas para uma liderança sustentável: um estudo subjetivo utilizando a metodologia Q. Escola Politécnica da Universidade de São Paulo - Departamento de Engenharia de Produção.

McKeown, M., Hinks, M., Stowell-Smith, M., Mercer, D., \& Forster, J. (1999). Q methodology, risk training and quality management. International Journal of Health Care Quality Assurance, 12(6), 254-266. https://doi.org/10.1108/09526869910291823

Noor, S., \& Arif, S. (2011). Achieving job satisfaction via workplace spirituality: Pakistani doctors in focus. European Journal of Social Sciences 19 (4), 507515.

Oliveira, D. H. de, Laurini, M. M., \& Santos, A. S. dos. (2020). Análise da relação entre a espiritualidade no ambiente de trabalho e o bem-estar laboral: percepção dos trabalhadores de uma cidade do interior do Rio Grande do Sul. Research, Society and Development, 9(9), e82996970. https://doi.org/10.33448/rsd-v9i9.6970

Pawar, B. S. (2009). Some of the Recent Organizational Behavior Concepts as Precursors to Workplace Spirituality. Journal of Business Ethics, 88(2), 245261. https://doi.org/10.1007/s10551-008-9961-3 
Research, Society and Development, v. 11, n. 2, e26711225648, 2022

(CC BY 4.0) | ISSN 2525-3409 | DOI: http://dx.doi.org/10.33448/rsd-v11i2.25648

Pauchant, T. (2002). Ethics na spirituality at work. Hopes and pitfalls of the search for meaning in organizations. Quorum.

Pereira, M. A., Fairweather, J. R., Woodford, K. B., \& Nuthall, P. L. (2016). Assessing the diversity of values and goals amongst Brazilian commercial-scale progressive beef farmers using Q-methodology. Agricultural Systems, 144, 1-8. https://doi.org/10.1016/j.agsy.2016.01.004.

Pinheiro, L., Froehlich, C., \& Konrath, K. (2019). Espiritualidade no ambiente de trabalho: Evidências em três casos. Desenvolve Revista de Gestão do Unilasalle, 8(2), 41. https://doi.org/10.18316/desenv.v8i2.5026

Prodanov, C. C.; Freitas, E. C.. (2013) Metodologia do trabalho científico: métodos e técnicas da pesquisa e do trabalho acadêmico (2a ed). Feevale,

Rego, A.; Souto, S.; Cunha, M. P. (2007). Espiritualidade nas organizações e comprometimento organizacional. RAE eletrônica, 6 (2), 1-27.

Rosa, E. (2013). Liderança e Espiritualidade. Universidade Federal de Pernambuco. Disponível em: http://www.homensdecoragem.org.br/2013/09/lideranca-eespiritualidade-por-eduardo-rosa/.

Robbins, S. P. (2010). Comportamento organizacional. (14a ed.) Prentice Hall.

Rodrigues, M. V. C. (2016). Qualidade de Vida no Trabalho: evolução e análise no nível gerencial. (15a ed.). Vozes.

Ruthes, V. R. M (2014). A relação entre espiritualidade e saúde: um novo paradigma. Saberes em Ação, 2(3), 1-6.

Rueda, F. Javier Marín, F., Ottati, P., Lariana P., Lima, T. H. \& Bueno, J. M. P. (2013). Construção e Validação de uma Escala de Avaliação da Qualidade de Vida no Trabalho. Avaliação Psicológica, 12(1), 43-50. http://pepsic.bvsalud.org/scielo.php?script=sci_arttext\&pid=S1677$04712013000100007 \& \operatorname{lng}=\mathrm{pt} \& \operatorname{tlng}=\mathrm{p}$

Silva, J. B., \& Silva, L. B. (2014) Relação entre religião, espiritualidade e sentido da vida. Logos \& Existência. Revista da Associação Brasileira de Logoterapia e Análise Existencial, 3 (2), 203-215. Disponível em: https://periodicos.ufpb.br/ojs2/index.php/le/article/view/22107

Sucesso, B., \& de Paula, E (1998). Trabalho e qualidade de vida. Dunya.

Tolfo, S. da R., \& Piccinini, V. (2007). Sentidos e significados do trabalho: Explorando conceitos, variáveis e estudos empíricos brasileiros. Psicologia \& Sociedade, 19(spe), 38-46. https://doi.org/10.1590/S0102-71822007000400007

Triviñòs, A. (1997). Introdução à pesquisa em ciências sociais: aspectos qualitativos em educação. Atlas.

Usman, A., \& Danish, R. Q. (2010). Spiritual consciousness in banking managers and its impact on job satisfaction. International Business Research, 3(2), 6572 .

Vaillant, G. (2010). Fé: evidências científicas. Manole

Vasconcelos, A. F. (2008). Espiritualidade no ambiente de trabalho: dimensões, reflexões e desafios. Atlas.

Vendramini, C. M. M., Santos, A. A. A. dos,Polydoro, S. A. J., Sbardelini, E. T. B., Serpa, M. N. F., \& Natário, E. G. (2004). Construção e validação de uma escala sobre avaliação da vida acadêmica (EAVA). Estudos de Psicologia (Natal), 9(2), 259-268. https://doi.org/10.1590/S1413-294X2004000200007

Waddock, S. A. (1989). Understanding Social Partnerships: An Evolutionary Model of Partnership Organizations. Administration \& Society, 21(1), 78-100. https://doi.org/10.1177/009539978902100105 